Tipología del artículo.

Cómo citar:

Editorial: Corporación Universitaria Minuto de Dios - UNIMINUTO.

Recibido: 30 de enero de 2018 Aceptado: 2 de abril de 2018 Publicado: 1 de agosto de 2018

Conflicto de intereses: los autores han declarado que no existen intereses en competencia.
Gleidy Alexandra Urrego Estrada

gleidy.urrego@gmail.com

Magíster en Hábitat, Universidad

Nacional de Colombia.

Administradora Pública, ESAP.

Doctorando en Ciencias Humanas

y Sociales, Universidad Nacional de

Colombia, Sede Medellín.

Jairo Fernando Niño jfninol@unal.edu.co

Magíster en Medio Ambiente y

Desarrollo. Administrador Público,

ESAP. Doctorando en Ingeniería -

Sistemas Energéticos, Universidad

Nacional de Colombia, Sede

Medellín.

Saida María Cardona saida.maria@botmail.com

Administradora Pública, ESAP.

\section{Aproximación reflexiva sobre la ética en el sector público en Colombia}

\section{A Reflective Approach to Ethics in the Colombian Public Sector}

\section{Aproximação reflexiva sobre a ética no setor público na Colômbia}

Gleidy Alexandra Urrego Estrada, Jairo Fernando Niño, Saida María Cardona

\section{Resumen}

Este escrito es de reflexión teórica en torno a la pregunta sobre la ética y lo público, especialmente, la relación entre la ética y el hombre público - servidor público- que es considerada en la acción pública y el bien común. En esa medida, la reflexión teórica central del presente escrito se centra en la ética de raíz weberiana en los conceptos de "responsabilidad" y "convicción", su relación con la nueva gestión pública, que está orientada a la eficiencia, eficacia y los resultados, como modelo de gobierno del Estado colombiano, en el cual el hombre público desarrolla su accionar y en el que es posible dar cuenta de los principios y valores de la ética de la responsabilidad y la convicción. No es una reflexión solo sobre la racionalidad de los valores - los medios y los fines que han de conducir la acción de este hombre - mediados por la responsabilidad y la convicción de este hombre público, sino, precisamente, reivindicar su humanidad ante un lugar público que cada vez enfrenta y lo pone en duda.

Palabras clave: ética, sector público, ética pública.

\begin{abstract}
This article is a reflection on the question about ethics and public matters, particularly the relationship between ethics and the public worker-public servant-that takes place in public action and the common weal. To that extent, the core theoretical reflection of this text revolves around Weber's ethics, in the concepts of responsibility and conviction, their relationship with new public management, which aims to efficiency, efficacy, and results, as the Colombian State's model of government, which allows to account for the principles and values of the ethics of responsibility and conviction. It is not only a reflection on the rationality of valuesthe means and ends that will guide this person's actions-mediated by
\end{abstract}


the responsibility of this public servant. Furthermore, it is an attempt to defend his/her humanity in the presence of a public place which faces and questions it.

Key words: ethics, public sector, public ethics.

\section{Resumo}

Este escrito reflete respeito a pergunta sobre a ética e o público, especialmente, a relação entre a ética e o homem público — servidor público- que é considerada na ação pública e o bem comum. Nessa medida, a reflexão teórica central do presente texto centra-se na ética de raiz weberiana, nos conceitos de "responsabilidade" e "convicção", sua relação com o novo gerenciamento público, que está orientada à eficiência, eficácia e os resultados, como modelo de governo do Estado colombiano, no qual o homem público desenvolve seu acionar e no que é possível dar conta dos princípios e valores da ética da responsabilidade e a convicção. Não só se trata de uma reflexão sobre a racionalidade dos valores —os meios e os fins que têm de conduzir a ação deste homem - meados pela responsabilidade e a convicção deste homem público, senão, também, de reivindicar sua humanidade ante um local público que a cada vez enfrenta e o põe em dúvida.

Palavras-chave: ética, setor público, ética pública.

\section{Introducción}

Es a la ética a la que corresponde determinar qué clase de hombre hay que ser para tener derecho a poner la mano en la rueda de la historia. Max Weber (El político y el científico).

El presente escrito da cuenta de la reflexión teórica en torno a la pregunta sobre la ética y lo público, esto como punto de partida que posibilita la pregunta sobre cuál es el sentido de la ética en lo público y en Colombia. De hecho, la importancia del presente escrito tiene su raíz necesariamente en la pregunta por quiénes ejecutan y representan lo público, es decir, lo público no solo recae en el Estado (lo institucional), sino en las diferentes prácticas y correlaciones de fuerzas producidas en las esferas sociales y culturales que, según Adrián Gurza (1998), configuran lo público, es decir:

Lo público es una dimensión social impuesta al Estado por la sociedad bajo una determinada correlación de fuerzas, en la que éste consigue poner al margen de la lógica del mercado un complejo de tareas socialmente necesarias para la reproducción y desarrollo de la sociedad como un todo (p.183).

Lo público no es un asunto metafórico, sino que tiene materialidad y, justamente, esa visibilidad recae mayormente en ciudadanos que tienen en su fuero ser servidores públicos, según los denominó la Constitución Política de Colombia de 1991 —especialmente en el artículo 123-. En esa medida, lo público para fines del presente escrito alude al hombre que se halla activamente vinculado a la vita activa, esto es, el hombre público - servido público-, quien se halla comprometido en hacer algo para el bien colectivo y ese mismo 
hacer está condicionado por el hecho de vivir contiguo a otros hombres, que por distintas razones no tienen su mismo fuero. Desde luego, este hacer tiene antecedente en lo que llamó Aristóteles biospolitikos. Al respecto señala Werner Jaeger citado por Arendt (2005, p. 53):

El nacimiento de la ciudad-estado significó que el hombre recibía además de su vida privada, una especie de segunda vida, su biospolitikos. Ahora todo ciudadano pertenece a dos órdenes de existencia, y a una tajante distinción entre lo que es suyo (idiom) y lo que es comunal (keinon).

Precisamente, lo comunal es en parte expresado a través del bien común, manifiesto en múltiples intereses de bienestar, que se resignifican en el vivir juntos, como señala Arendt: “[...] vivir juntos en el mundo significa en esencia que un mundo de cosas está entre quienes lo tienen en común al igual que la mesa está localizada entre los que se sientan alrededor; el mundo, como todo lo que está en medio, une y separa a los hombres al mismo tiempo" (2005, p.73).

Ese bien común o lo que se tiene en común es antecedido y mediado por la libertad que promueve el Estado contemporáneo, que Jean-Jacques Rousseau asertivamente distingue en tres tipos de libertades, en su texto El contrato social, publicado en 1762, en donde hace un distanciamiento de la concepción libertad en la polis griega, en la medida en que hay tres tipos de libertad. La primera: los hombres nacen libres e iguales por naturaleza y se pierde la libertad tras realizar o establecer una relación contractual con otros para someterse voluntariamente a reglas y beneficios de intercambio social; la segunda, la libertad civil que es limitada por la voluntad general, producto de las relaciones sociales, donde hay un Estado mediador de las relaciones privadas entre los hombres; la última libertad es la moral, en la que los hombres son dueños de sí mismos.

Esta última libertad tiene su cuestión en la ética, que se deriva del vocablo ethiké, de una misma raíz semántica, antecedida del grupo êthos (carácter) y êthos <mos-moris> (costumbres). Con esto se quiere decir que la moral tiene un sentido en la ética, es decir, en lo virtuoso de hacer el bien como el hábito en el cual se hace lo bueno y realiza bien lo que se le ha confiado. También envuelve intensamente acciones que involucran lo colectivo - comunal- y sobre estas es necesario deliberar. Esto implica la responsabilidad del hombre público — servidor público - frente a las actuaciones y los medios que emplea y que son mediados en y por una virtud ampliamente reconocida.

Así que ¿cuál es el fin de las acciones del hombre público, si los medios y el fin se han configurados como sinónimos ?'Y ¿ ¿el fin de estas acciones están condicionados por códigos socioculturales? Ahora bien, estos interrogantes tienen su condición de posibilidad en lo que en Aristóteles se interpreta como la manera de proceder del ser humano, la acción y la elección. Es por esto por lo que lo público, para fines del presente escrito, se amplía sobre quienes son la materialidad de la organización y del gobierno. Así lo señala North: "las instituciones son una creación humana, evolucionan y son alteradas

1 Aquí Martha Nussbaum (2004) en un aparte de su texto La fragilidad del bien aborda los fines y los medios en un contexto ético, al indicar: "En efecto, se ha señalado que Aristóteles dice explíitamente que la deliberación y la elección se relacionan, no con los fines sino con los medios para esos fines. Ahora bien, cabría firmar entonces que, después de todo, aquello a lo que atañe la elección, incluido los valores que constituyen la vida humana buena, debe entenderse como medios (comparables) para algo que se encuentra más allá que ellos (la felicidad)" (p. 380). 
por humanos; por consiguiente, nuestra teoría debe empezar con el individuo (1993, p. 14). Precisamente en North se justifica que quienes hacen parte de lo público, institucionalmente hablando, son a quienes se les debe empezar a interrogar por ¿cuál es el fin y motivación de a sus actuaciones? ¿Estas responden a un ordenador sociocultural?

En tanto, las actuaciones inciden y son incididas por procesos socioculturales vinculantes, que asocian pensamiento y acción. Esto es, la acción humana es cocreadora, posibilita una mixtura de ideales que los hombres van a hacer y pueden hacer, y que en la ética se incorporan a través de medios y actuaciones que los hombres reconocen como virtuosas, es decir, de buen nombre. Por ello, en lo público, entendido como lo gubernamental, la ética manifiesta la plena capacidad de juicio de los hombres públicos que hacen parte de este, como un acto que Aristóteles señala voluntario, ya que este acto se hace por el deseo del hombre y está dentro de su poder como producto de una deliberación de lo que puede hacer y sobre los medios para lograrlo, porque siempre hay un fin y una responsabilidad del hombre sobre ese acto voluntario.

La ética en la política y el sector público tiene su condición de posibilidad en la capacidad de reflexión y elección de quienes ejercen funciones gubernamentales, entendida como la construcción de una ruta por la cual transitar y la configuración de virtudes como aquellas actuaciones y cualidades que pasan por la búsqueda del bien común, constituido como unos de los fine del estado moderno. Así, en el arte de gobernar, en el ejercicio del poder y en los asuntos que afectan el interés común, la ética de transcender se sitúa en el gobernar al servicio del bien colectivo, como manifiesta Marco Aurelio en su escrito Meditaciones (libro VII, p. 55): "La política pretende encontrar la mejor forma de constituir un Estado y ésta será aquella constitución que le brinde mayores oportunidades para alcanzar lo justo y esto es el bien común”.

Por su parte, es necesario resaltar que la reflexión ética en Max Weber (1984) es abordada a través de los conceptos de "responsabilidad" y "convicción", es decir, una ética propia al individuo y una ética de la responsabilidad propia a su quehacer político (toda actuación tiene una decisión y por tanto un compromiso); ambas se integran, se interpelan - no son opuestos-, son deseables y necesarias en la conducta del hombre político-público. El primer concepto da cuenta de las posibilidades y las consecuencias que se derivan de una determinada decisión que supone todo acto voluntario del hombre público; al tiempo, confronta los medios con los fines en la medida en que es una manifestación racional que valora los fines y los medios que envuelven la acción pública y el bien común. El segundo concepto, por su parte, da cuenta del convencimiento moral que tiene el hombre público sobre la acción pública y el bien común.

De este modo, es necesario aclarar que la reflexión teórica central del presente escrito se centra en la ética de raíz weberiana, que se fundamenta en un acumulado de valores que se practican en cada grupo político y social, y ello implica un conocimiento de sí mismo, tal como pensaron los griegos, que antes de gobernar o poder gobernar, el hombre debe gobernase a sí mismo. El autor señala: "[...] el político tiene que vencer cada día y cada hora un enemigo muy trivial y demasiado humano, la muy común vanidad enemiga mortal de toda entrega a una causa y de toda mesura en este caso de la mesura a sí mismo" (p. 154). 
Así que la ética en la política y lo público alude a una ética aplicada que reflexiona los problemas morales que enfrenta el hombre público, es decir, aquel que tiene visibilidad en la esfera de lo estatal y lo político; estos problemas del hombre público pasan por la acción pública y el propósito colectivo de lograr el bien común. De hecho, la ética de la responsabilidad y la convicción posibilita un pensamiento crítico en el hombre público, mediante cuestionamientos que atraviesan un saber (creencias, conocimiento) y un gobierno (institucionalidad, poder), esto es, ¿̇cómo y por qué actuar? ¿Qué es lo más conveniente para mí, la institucionalidad pública, el interés común? ¿Si actúo así qué obtendré?

Lo anterior necesariamente comprende una decisión que otros, en este caso un colectivo considerable y una institucionalidad, aprueban o desaprueban en relación con valoraciones establecidas sociocultural y jurídicamente. Justamente el hombre público teje compromisos no reservados al interés privado, sino en procura del bien colectivo, y su quebrantamiento desencadena deslegitimidad de lo político y lo público. En tanto, la ética es una construcción moral propia y colectiva que constantemente genera rasgos de coherencia entre decisión y acción en clave del bien colectivo en el carácter y la costumbre del hombre público.

Ahora bien, la orientación metodológica del presente escrito es teórico-reflexiva y está organizada en dos momentos: el primero, revisión literaria alrededor de categorías como ética, la función pública y la gestión pública, y un segundo momento de análisis de los contenidos de dicha revisión. En esa medida, el orden expositivo del presente escrito contempla, en una primera parte, la relación de la ética con la nueva gestión pública como modelo de gobierno del Estado colombiano, en el cual el hombre público desarrolla su accionar y en el que es posible dar cuenta de los principios y valores de la ética de la responsabilidad y la convicción; en la segunda parte se aborda el servicio público, la función pública y la carrera administrativa desde una reflexión ética y, en la última parte, se desarrolla la reflexión sobre el código de ética y su importancia en las actuaciones del ejercicio público.

\section{Desarrollo}

\section{La ética y la nueva gestión pública: principios y valores}

Para este apartado la gestión pública se considera como el modelo de gobierno del Estado colombiano moderno, en el que el hombre público - servidor público- desarrolla su accionar y en el que es posible dar cuenta de los principios y valores de la ética de la responsabilidad y la convicción, esto de la ética en el sector público. La nueva gestión pública da cuenta de la eficacia, eficiencia, resultados y sitúa el quehacer del Estado y la administración pública a partir de competencias y capacidades fiscales, administrativas y políticas que son propias de los gobiernos locales. Al respecto indica Urrego (2015):

Es así como en Omar Guerrero (1990), la gestión pública o la new public management es el enfoque del nuevo manejo público, es esto es, la capacidad gubernamental de mirar introspectivamente los procesos de la administración pública, como ciencia del accionar administrativo entre lo público, político y social. (p. 62) 
Por ello, la administración pública en Colombia tiene su basamento en la nueva gestión pública, que también introduce en el quehacer público nuevos valores que están vinculados a la ética del deber y la responsabilidad, ambas desde los efectos e implicaciones de las acciones de quienes representan el Estado. En Oscar Bautista (2007) es necesario identificar actitudes, ya que su accionar está sujeto a la visibilidad de los ciudadanos y de los medios de comunicación. Así, el fin que busca la política y lo público radica en el interés o bien común como es trabajar por la paz y el desarrollo de los pueblos que, desde la ética, quienes gobiernan están llamados a pensarse a sí mismos y autoconocer sus acciones.

La tarea de autoconocerse implica dimensionar las actitudes como la forma de comportamiento que tienen los seres humanos; a su vez, considerar las aptitudes como capacidades cognoscitivas, emocionales, estéticas, corporales, entre otras. En esa medida, evoca situarse inevitablemente en cánones determinados como son los principios que ciertamente generan un sistema de valores que cada persona adscribe; asimismo, son postulados que el sujeto asume como orientación de todas sus actuaciones. Los principios dan origen a los valores, cuyo contenido desencadena una serie de preceptos y horizontes de sentido ético.

Por su parte, la USAID (2006) (United States Agency for International Development, por sus siglas en inglés) busca fortalecer, en la misma línea de la nueva gestión pública, los principios de una ética de lo público, esto a partir de la consolidación de un sistema de normas o ideas fundamentales que rigen el pensamiento o la conducta del hombre, es decir, los principios y los valores que todo hombre público debe tener. En esta línea, los principios éticos en el sector público "[...] son las normas internas y creencias básicas sobre las formas correctas como debemos relacionarnos con los otros y con el mundo" (p. 26). Tienen un propósito sociocultural y determinan conductas que desde la ética se establecen como lineamientos que se deben seguir por el hombre público. Por último, los principios regulan las actuaciones del hombre público, como un camino que logra algún tipo de unanimidad y en los valores se refuerza. Señala la USAID (2006, p. 26):

Por ejemplo, un principio es la prevalencia del interés general sobre el interés particular; de allí se derivan, precisamente, los valores de la transparencia y de la honestidad. Como puede observarse, el enunciado de un principio no debe ser una palabra, sino una frase cuyo contenido es un precepto.

Otros principios éticos en el ejercicio de la función pública son:

- El interés general prevalece sobre el interés particular.

- Es imperativo de la función pública el cuidado de la vida en todas sus formas.

- Los bienes públicos son sagrados.

- La finalidad del Estado es el mejoramiento de las condiciones de vida de toda la población.

- La función primordial del servidor público es servir a la ciudadanía.

- Quien administra recursos públicos rinde cuentas a la sociedad sobre su utilización y los resultados de su gestión. 
- Los ciudadanos tienen derecho a participar en las decisiones públicas que los afecten.

Los valores en el ámbito de lo público se encaran y tiene su condición de posibilidad en los modelos de gestión ética, que la usaid ha definido como:

Aquellas formas de ser y de actuar de las personas que son altamente deseables como atributos o cualidades nuestras y de los demás, por cuanto posibilitan la construcción de una convivencia gratificante en el marco de la dignidad humana. Los valores usualmente se enuncian por medio de una palabra (Honestidad, responsabilidad, cumplimiento, etc.). (p. 26).

Precisamente, es necesario defender los valores en el poder público, a partir de orientar y articular el deber ser (principios y disposiciones constitucionales) y el poder hacer hacia convicciones, acciones y finalidades del bien común que descansa en los hombres que son altamente visibles ante otros, como señala Fereira (2005, p. 8):

Los Valores Supremos, son aquellos que trascienden en el tiempo: verdad, justicia, belleza, integridad, libertad, paz. Los Valores instrumentales o medios para alcanzar los valores esenciales: el trabajo, la productividad, la economía, el respeto a la autoridad, la libertad de expresión, desarrollo de personal, la igualdad de oportunidades.

Es así como los principios y valores éticos en el sector público se resumen en: i) servir a los demás a través de la política y ii) la libertad del hombre para gobernarse a sí mismo y a otros. También esto, en la ética weberiana, está acompañado de actuaciones eficaces y eficientes de quienes ejercen funciones estatales, pues la sociedad demanda resultados, pero desde una moderna, ordenada y racional administración de los recursos públicos. Como vuelve a indicar la USAID: "[...] cumplir cabalmente con los postulados y mandatos de la Constitución y la Ley acerca de cómo debe ejercitarse dicha función, en términos de eficiencia, integridad, transparencia y orientación hacia el bien común" (p. 2). En este sentido, a partir de Weber (véase tabla 1) se estableció para la nueva gestión pública un decálogo de valores éticos a considerar para lo político y público, que se cimienta en la integridad de las acciones públicas y el bien común.

Tabla 1. Valores en el modelo weberiano

\begin{tabular}{|l|l|l|}
\hline \multicolumn{2}{|c|}{ VALORES EN EL MODELO WEBERIANO } \\
\hline Autoridad & Integridad & Objetividad \\
Capacidad & Jerarquía & Permanencia en el empleo \\
Diligencia & Lealtad & Profecionalización \\
Disciplina/Obediencia & Legalidad & Racionalidad \\
Espíritu de servicio & Merito & Rigidez \\
Imparcialidad & Neutralidad & \\
\hline
\end{tabular}

Fuente: Bautista (2007, p. 79) 
Los anteriores valores fueron retomados en la Constitución Política Colombiana de 1991, a partir de una ética de la responsabilidad, es decir, de lo debido (ética deontológica), de quien representa lo público-político, a partir de conocer y aceptar las consecuencias de los actos y la capacidad para resarcir algún daño a que haya lugar. Este valor se evidencia en el Estado social de derecho, que implica un compromiso estatal por garantizar el bien e intereses comunes, como deber ético-moral de establecer un conocimiento general de lo correcto, como la prevalencia de lo colectivo. A su vez, la Constitución Política, desde lo axiológico, establece un Estado social de derecho, a partir del reconocimiento de una serie de derechos modernos, cuya base consuetudinaria es ética y moral, en la medida en que ordena las actuaciones del Estado y los ciudadanos a límites y conductas ideológicas y socioculturales de lo individual-colectivo como interdependiente lo uno de lo otro. Por último, un Estado democrático que fortalece la libertad, la participación e inclusión ciudadana. Así lo señala Touraine (1994/2000, p. 35): "La democracia no nace del Estado de derecho sino del llamado a unos principios éticos - libertad, justicia - en nombre de la mayoría sin poder y contra los intereses dominantes".

Los anteriores elementos están en consonancia con los valores weberianos que, sin embargo, no se han fortalecido a partir de la implementación de técnicas del sector privado al sector público, en el que todo el quehacer estatal se traduce en gestión de procesos y, ante todo, de resultados. Es así como los valores y principios éticos en el sector público colombiano son mediados en la clasificación de conductas de quienes representan lo público, se direcciona a productos eficientes y estandarizados, que se miden en el desempeño de quienes representan el Estado. Es decir, por una parte, la ética del que llamamos servidor público tiende a ser evaluada, condicionada e impuesta en la medición del desempeño cuantitativo de las funciones públicas. Por otra parte, los principios y valores éticos en el sector público no se allanan completamente a partir de dimensionar, discutir y crear consenso en tres formas de pensamiento ético, entre lo que hemos denominado el ordenador ideológico y sociocultural que establece el modelo de valores y conductas socioculturales de los hombres, con una ética de principios y valores de lo público para lo público, que en Weber podríamos leer como ética de responsabilidad y convicción.

A partir de la Constitución política de 1991 hasta la actualidad, la orientación de la política y la administración pública colombiana se ha direccionado a poder gobernar con programas de ajuste económico y fiscal. El desgaste del modelo burocrático produjo la desregularización y reformas constitucionales que redujeran el tamaño del Estado y que hicieran que sus funciones fueran precisas. Esto implicó un modelo gerencial enfocado en una cultura administrativa, el ciudadano como cliente, eficiencia económica y reglamentar un gobierno limitado. Por otra parte, incluyó un modelo posgubernamental, centrado en reformas, deberes del Estado, saneamiento y racionalización de las finanzas públicas y gestión por resultados. Al respecto, Gunn (1996, p. 43) señala:

La gestión pública acepta que el sector público comparte con el privado la necesidad de lograr objetivos de la forma más económica y más eficiente posible a través de estrategias coherentes, de tácticas y de estructuras apropiadas, de un personal motivado o de técnicas gerenciales adecuadas para desplegar y controlar la utilización de recursos organizativos financieros, humanos, materiales, informativos, etc. 
Sin embargo, en el marco de la nueva gestión pública, totalmente económica y fiscal, el actuar de quien representa el Estado no es lo deseado, pese a que la construcción ética en Colombia esté fuertemente vinculada con la moral religiosa judeocristiana, como indica Vanegas (2010, p. 89):

Esto significa (refiriéndose a la Constitución Política de 1886) que la responsabilidad individual estaba sujeta a la creencia en el Dios católico. Él era el modelo ético que había que seguir y era la justificación de los comportamientos morales. Esto implica una concepción ética teologista, que se justifica a partir de un ser transcendental, omnipotente y omnisciente.

De manera que la nueva gestión pública apuntala la configuración de principios y valores no religiosos, sino racionales que se instalen en el actuar de quienes representan el Estado, mediante el bien común, como interés ampliamente compartido y coherente con un estilo de gobernar técnico-reflexivo. Este estilo está enmarcado en el establecimiento normativo de nuevos valores de corte posweberiano, esto es, basados en una ética de la responsabilidad, aplicada al servicio público estatal: atención al ciudadano, calidad, competitividad, eficacia, eficiencia, flexibilidad, individualidad, imparcialidad, objetividad, productividad, profesionalidad, rigidez y transparencia.

\section{El servicio público, la función pública y la carrera administrativa desde la reflexión ética}

La ética en lo público necesariamente aborda no solo la acción pública y el bien común, sino la institucionalidad y funcionalidad del quehacer público, por ello, el servicio público $^{2}$ relaciona una lectura sobre la responsabilidad del Estado sobre sí mismo y hacia sus ciudadanos, a partir del cuestionamiento de cómo es el deber ser - convicción- y el querer ser - responsabilidad- del hombre público. Es decir, la ética en lo público devela el carácter y la practicidad de la acción gubernamental y la forma con que el servidor decide pluralmente construirse en relación con sus responsabilidades altamente visibles por y para el ciudadano, que de una u otra forma vigila sus actuaciones y discursos. Al respecto Adela Cortina (1998, p. 155) apunta:

Cualquier ética que se presente en una sociedad pluralista tendrá pretensiones de publicidad, es decir, deseará presentarse en público, expresarse en público y servir para el público. Sólo que hay un tipo de ética específica de quienes ingresan en el mundo de la Administración Pública, a la cual convendría entonces denominar para evitar confusiones, Ética de la Administración Pública, de la Función Pública o del Servicio Público.

2 El artículo 365 de la Constitución Políica de Colombia de 1991 establece: "Los servicios públicos son inherentes a la finalidad social del Estado. Es deber del Estado asegurar su prestación eficiente a todos los habitantes del territorio nacional. Los servicios públicos estarán sometidos al régimen jurídico que fije la ley, podrán ser prestados por el Estado, directa o indirectamente, por comunidades organizadas, 0 por particulares. En todo caso, el Estado mantendrá la regulación, el control y la vigilancia de dichos servicios. Si por razones de soberanía 0 de interés social, el Estado, mediante ley aprobada por la mayoría de los miembros de una y otra cámara, por iniciativa del Gobierno decide reservarse determinadas actividades estratégicas o servicios públicos, deberá indemnizar previa y plenamente a las personas que en virtud de dicha ley, queden privadas del ejercicio de una actividad lícita". 
Por otro lado, el servicio público, que tiene un sentido ético, es antecedido, como indica Sergio Valls ${ }^{3}$, por el vínculo del régimen jurídico con respecto al derecho civil, que considera distante con el derecho administrativo, que tiene como fundamento la confrontación del gobernante con los gobernados. Esto abre la reflexión de sacar del anonimato u ocultamiento la ética y exteriorizarla en el ejercicio de lo público, a partir de descifrar sus condiciones de funcionamiento como el eficientismo versus responsabilidades que se adquieren en la toma de decisiones y que comprometen la formación del servidor público de manera personal y, en especial, articulada con intereses colectivos que representa. Señala Sergio Valls (2009, p. 430):

Las exigencias de las sociedades que se van extendiendo claman una interacción del ciudadano con las autoridades definiendo el bien público que debe ser atendido por los gobiernos democráticos. Las posturas teóricas se dieron en dos extremos: quienes conciben el estado esencialmente como un prestador de servicios públicos, incluso cuando ejerce actos de autoridad y quienes definen al estado como una autoridad, capaz de excluir cualquier actividad económica del mercado y convertirla en pública, sin que necesariamente en ninguno de los dos extremos se garantice la satisfacción del interés público.

Esa forma de funcionamiento anteriormente señalada radica en la concepción del derecho administrativo, que permitió identificar las diferentes actividades estatales y la clasificación de las mismas, y también distingue entre las personas jurídicas tanto orgánicas como funcionales. El derecho administrativo concibe el concepto de servicio público y, en especial, el de interés público, siempre superior al derecho privado. Existen diferentes condiciones de funcionamiento del ejercicio del servicio público, que emerge del derecho administrativo y relaciona la ética, a partir de teorías referentes al servicio público ${ }^{4}$. Por su parte, Jorge Fernández (2004, p. 50) hace una síntesis de las principales posturas frente a este tema, a saber:

a. Teoría propuesta por León Duguit, que considera al servicio público como toda actividad que debe ser asegurada, reglada y controlada por los gobernantes.

b. Teoría formulada por Gastón Jéze, conforme a la cual el servicio público viene a ser toda actividad de la administración pública.

c. Teoría promovida por Maurice Hauriou, que entiende al servicio público como una parte de la actividad de la administración pública.

d. Teorías que conceden escasa o ninguna importancia a la noción de servicio público, entre las que figura la presentada por Henri Berthélemy, para quien la noción de servicio público carece de importancia, por considerarla como un cajón de sastre donde se reúnen instituciones tan disímbolas como 'una corte

3 La Noción del Servicio Público en el Estado Social de Derecho.

4 También la Corte Constitucional, a través de la sentencia C-043 de 1998, expresó: "El derecho positivo colombiano define el servicio público como '... toda actividad organizada que tienda a satisfacer necesidades de interés general en forma regular y continua, de acuerdo con el régimen jurídico especial, bien que se realice por el Estado directa 0 indirectamente 0 por personas privadas'” (artículo 430 del Código Sustantivo del Trabajo). 
de apelación, una institución de beneficencia, una caja de ahorro, un ferrocarril metropolitano, la imprenta nacional, etc..

En tanto, en el quehacer del hombre público — servidor público - descansa la labor de prolongar el fin del Estado y, así, asegurar la satisfacción de la calidad de vida de los ciudadanos. Pero en este quehacer, el funcionamiento de la ética es mediada por la tecnicidad y deja poca autonomía para que el servidor público decida cómo producir su vida, a través de prácticas éticas como la idea de que la finalidad del Estado es para todos, no para algunos, y los recursos públicos se destinan conforme a consensos colectivos y legitimados (normatizados). A su vez, como el funcionamiento de la ética en el servidor público se produce en el campo de la posibilidad de dominar sus deseos y distanciarse de las verdades construidas en torno al Estado fundado por muchos hombres públicos como corrupto, para posibilitar otras formas de ejercer lo público en consonancia de mejorarse asimismo en relación con lo otro (el ciudadano).

Por lo demás, abordar la ética en el servicio público implica que se debata la relación del hombre público y la institucionalidad, es decir, la institucionalidad establece un derrotero de cómo actuar, pero esto diluye la reflexión del hombre público sobre su actuación desde sí mismo hacía la defensa del bien común, ya que se cualifica la política en el eficientismo gubernamental. En tanto, superar la ética pública como un código de actuación, antes bien, como reflexión fundante de pensamientos, capacidad y comportamiento frente al ideal de salvaguardar mediante rango constitucional los derechos sociales, económicos y culturales de los habitantes. Luego de más de 20 años de vida constitucional "democrática" los derechos de los ciudadanos solo pueden ser respetados $\mathrm{y}$ atendidos eficazmente, mientras el hombre público actúe bajo el requisito sine qua non de asumir la ética en cualquier decisión pública.

La Constitución Política de 1991 presume que el servidor público indisolublemente es ético, por cuanto su actuación es inherente a la finalidad social del Estado. A su vez, la instrumentalización del servicio público a través de la función pública, empleo público y carrera administrativa es un asunto condicionado al deber ser eficientista con dicha finalidad estatal. Si bien la ética se asume en el ejercicio del servicio público, no se evidencia como ejercicio que emana del propio hombre público, a partir de la libertad y la responsabilidad, que genera otras formas y significados de dar continuidad, de manera autónoma con el proyecto del bien común, que es la esencia del Estado colombiano. Sin embargo, la presunción de la ética en la función pública y el empleo público parece limitarse a condiciones normativas que buscan simplemente legitimidad en procesos mediados por prácticas clientelistas 5 . Nótese que la figura 1 muestra la medición de la ética a

5 Los cargos públicos son ocupados con nombramientos provisionales sin el lleno de los requisitos de estudio y experiencia, como contraprestación por favores políticos. Este tipo de ingreso al servicio público buscaba promover la figura de la inscripción extraordinaria en la carrera administrativa. Adicionalmente a esto, un alto porcentaje del recurso humano al servicio del Estado ingresa mediante contrato de prestación de servicios profesionales o de apoyo a la gestión. Con la expedición de la Ley 909 de septiembre 23 de 2004, se desarrolla el capítulo II de la Constitución Políitica referente a la Función Pública (artículos 122 a 131). Esta ley tiene por objeto regular el sistema de empleo público, la carrera administrativa y la gerencia pública. La ley aplica para las entidades que hacen parte de la Rama Ejecutiva del nivel nacional y entes descentralizados con excepción de quienes se les aplican las carreras especiales debido a la especificidad de las funciones que cumplen. La Ley 909 institucionaliza la carrera administrativa y los criterios para acceder a ella son el mérito y la igualdad. Otro aspecto importante en esta Ley fue el desarrollo del artículo 130 de la Constitución de 1991: "habrá una Comisión Nacional del Servicio Civil responsable de la administración y vigilancia de las carreras de los servidores públicos, excepción hecha de las que tengan carácter especial". 
partir de competencias, dadas en el hacer, saber y ser, además diluida en la valoración del cumplimiento de metas institucionales y en las competencias laborales, que presumen un hombre público profesionalizado para el quehacer público, donde la ética se construyó en el proyecto académico individual, servida por el sistema de educación.

Figura 1. Manual de funciones y evaluación del desempeño.

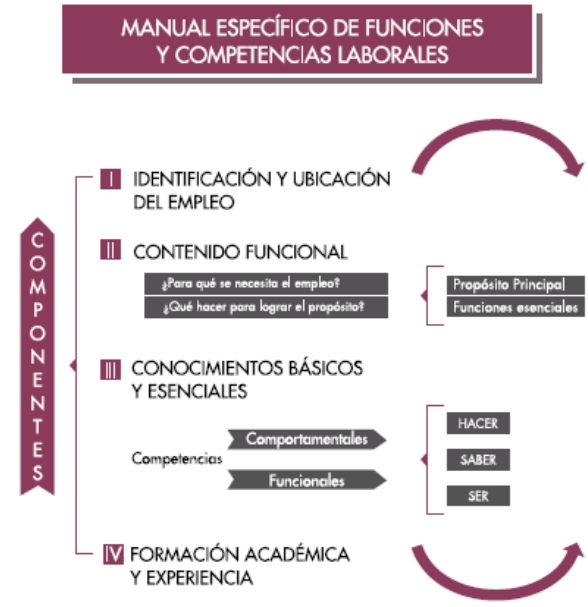

Fuente: Presentación EDL - Comisión Nacional del Servicio Civil y Guía para establecer o modificar el Manual Específico de Funciones y Competencias Laborales, 2014. p. 22.

En esa medida, el manual de funciones ${ }^{6}$ y la evaluación del desempeño ${ }^{7}$ que se hace sobre el hombre público, la ética, si bien no es tema explícito, debe ser considerado como un campo de continua reflexión y horizonte donde precisamente no solo se determine desde las competencias, formación académica y funciones del hombre público, sino

Esta Comisión tiene la responsabilidad de hacer que efectivamente los concursos públicos para proveer los cargos vacantes y en provisionalidad se realicen de manera transparente para que las personas más idóneas ética y profesionalmente sean quienes ocupen los cargos públicos. Sin embargo, el primer concurso abierto que convocó la Comisión a finales de 2005 se interrumpió para atender las mismas exigencias dilatorias de tiempo atrás con respecto a la inscripción extraordinaria en la carrera administrativa de los cargos ocupados con nombramientos provisionales. Esta fue la pretensión del Acto Legislativo 01 de 2008, que buscada modificar el artículo 125 de la Constitución. Por fortuna, este desacierto fue resuelto por la Corte Constitucional en la sentencia C-588 de 2009 declarando inexequible este acto legislativo, defendiendo el principio del mérito y la igualdad como único requisito para acceder a la carrera administrativa.

6 Al Departamento Administrativo de la Función Pública le corresponde fijar el procedimiento para establecer 0 ajustar los manuales específicos de funciones en todas las entidades del Estado. El gobierno nacional y el Dafp, mediante decreto, establecen las funciones y los requisitos generales para los empleos públicos de los distintos niveles jerárquicos de los organismos y entidades del orden nacional. Esta norma es el modelo para que cada entidad pública establezca 0 modifique el Manual Específico de Funciones y Competencias Laborales. Con el reciente Decreto 1785 de septiembre de 2014, el gobierno nacional pretende desarrollar el numeral 7 del artículo 40 de la Constitución Políitica que dice "acceder al desempeño de funciones y cargos públicos...". Con esta nueva normatividad se unifica y adecua la reglamentación de los manuales de funciones y competencias laborales, incluyendo en los mismos la clasificación de los diferentes programas académicos agrupados por áreas de conocimiento y núcleos básicos de conocimiento, adopta el Sistema Nacional de Información de la Educación Superior (swies), establecido en el Decreto 1767 de 2006.

7 "Noción y objeto de evaluación. La evaluación del desempeño laboral (EDL) es un proceso administrativo de gestión individual y colectiva, que busca verificar, valorar y calificar el desempeño de un servidor en el marco del propósito principal, las funciones y responsabilidades del empleo, con condiciones previamente establecidas en la etapa de fijación de compromisos laborales y comportamentales, su aporte al logro de las metas institucionales generando valor agregado a las entidades". (Art. 1. . Acuerdo n. ${ }^{0} 138$ de 2010). 
también se cuestione la finalidad de toda actuación del hombre público. Es decir, ¿acaso la ética se evalúa de forma eficiente, de 'cumplió' o 'no cumplió, sin adentrarse a cuestionar los beneficios de los medios y los fines dentro del quehacer público? Por tanto, el manual de funciones y la evaluación del desempeño simplemente son formas y códigos que dicen cómo actuar; el trascenderlos implica que el hombre público debe gobernarse a sí mismo, esto entendido como la relación que el hombre público tiene frente a sí mismo, y si los principios y valores que profesa y evidencia en su actuar están en función de lo colectivo, en este caso, de lo público.

\section{Código de ética: ética y transparencia en las actuaciones del ejercicio público}

\section{La ética no es un código, es la reflexión de cada persona sobre la libertad, lo que quiero ser, cómo vivir mejor libre y plenamente.}

Fernando Savater

En las actuaciones del ejercicio público, la ética precisamente se problematiza desde la libertad que tiene toda persona para actuar, esto mediado por un contexto, intereses personales (percepciones, afirmaciones) e intereses institucionales (finalidad de la institucionalidad pública), de forma razonable, que procuren una finalidad. En esa medida, la ética en el ejercicio público se centra en actuaciones que procuran el resultado del bien común, contenido en la Constitución Política de Colombia de 1991 en los fundamentos del Estado.

A su vez, todos los intereses individuales de quienes representan el Estado en sus acciones deben ser resueltos desde el ámbito privado y armonizados con los intereses colectivos, que son construcción sociocultural. En tanto, el modelo de administración de lo público en Colombia, a partir de la década del 90 y en el marco de la gestión pública, procura resultados medidos bajo indicadores de eficiencia y eficacia. Por tanto, la ética se incorpora en esta lógica con requerimiento de transformación de la administración del Estado, a través de un modelo de gestión que implica definir cuáles son las acciones conducentes que permiten la consecución de objetivos determinados en un proceso de planificación y ejecución pública. Según Bautista (2007, p. 110), los códigos de ética en el ejercicio de lo público fueron antecedidos:

En los años setenta en los Estados Unidos a raíz del escándalo "Watergate" que terminó con la renuncia del presidente Richard Nixon. Este hecho demostró al público que algunos gobernantes y funcionarios practicaban conductas inmorales o antiéticas. Es entonces cuando se crean mecanismos para el fomento de la ética, como por ejemplo la Oficina de Ética y la Ley de Ética en el Gobierno, ambas creadas en 1978... En 1976, un grupo de trabajo sobre ética perteneciente a la Asociación Internacional de Escuelas e Institutos de Administración Pública (Iasia), organismo que agrupa a directores de Escuelas e Institutos de Administración Pública de distintas partes del mundo, acordó instar a varios centros académicos a que incluyesen la ética como asignatura esencial para la formación de los gestores públicos. 
En esa medida, la ética interesa a la administración de lo público por medio del Código de Ética, para prevenir y corregir conductas indebidas contrarias a la finalidad del Estado. También, por este se presume la aprehensión y aplicación de la cultura ética al servicio de los ciudadanos. En el ejercicio de lo público, la USAID (2006) estableció como referente el Modelo de Gestión Ética para entidades del Estado ${ }^{8}$. El enfoque de este modelo es la tradición racionalista, que se fundamenta en la reflexión filosófica de la ética como sistema normativo e instrumental y la teoría de los valores, como ejes para la fundamentación deóntica. Si bien, asume la ética como la preocupación por el bienestar del otro en términos de derechos, deberes, responsabilidad y cuidado, es necesario cuestionar ¿̇ómo armonizar los intereses individuales, y cuestionarlos con los intereses colectivos, cuando el contexto y la misma formación del sujeto público exige la victoria del primero a costa del segundo?

Por consiguiente, la pretensión de este modelo se afinca en establecer un horizonte de sentido ético para el ejercicio público, que evidencia establecer otros horizontes que aborden la interpretación de la naturaleza ética no ajena a todo discurso administrativo, puesto que su fundamento es la vida y las interacciones - socialización - entre todos los sujetos. Por ello, las emociones son componente de la ética; estas, a su vez, están influenciadas por la cultura en que se desenvuelve cada sujeto (las costumbres, las reglas). Por tanto, la ética en el ejercicio de lo público es visible y surge como una condición básica y natural de la convivencia social del Estado. En los lineamientos del ejercicio de lo público, el código de ética, según la USAID (2006), responde a la gestión ética que en la administración del Estado se debe alcanzar, como gobierno del Estado sobre sí mismo. Sobre la gestión ética señala la USAID (2006, p. 48):

La gestión ética es la actuación autorregulada de los agentes públicos, orientada a asumir sus responsabilidades frente a los grupos con los que interactúan, a encaminar sus acciones hacia el establecimiento de modelos de trabajo orientados por la ética pública a ajustar los planes estratégicos y estructuras organizacionales hacia la búsqueda de los fines sociales que garanticen la aplicación de los Derechos Humanos integrales y el mejoramiento de las condiciones de vida de toda la población —en especial de la más vulnerable — según lo ordenan la Constitución y la Ley.

Nótese que el código de ética está vinculado a una intención de ordenar las actuaciones, valores y principios de quienes ejercen lo público, a través de la instrumentalización y formalismo, a su vez, exigencia de organismos internacionales, de todo un proceder y finalidad del servicio público. Por tanto, este código alude a una norma que regula comportamientos de los servidores dentro de una organización pública, es de obligatorio cumplimiento y su deber ser radica en establecer estándares de actuación para los servidores, más que criterios. Así que el deber ser del código de ética consiste en que toda

8 Modelo de Gestión Ética para entidades del Estado elaborado por el programa Eficiencia y Rendición de Cuentas en Colombia de la Agencia de los Estados Unidos Para el Desarrollo Internacional (USAID), operado por Casals \& Associates Inc. Publicación financiada por el Gobierno de los Estados Unidos de América, a través de USAID. Este modelo es una herramienta para gestionar el fortalecimiento de la ética pública en el ejercicio de la función administrativa. Aborda un conjunto de conceptos, metodologías, procedimientos e instrumentos que son el marco de referencia para el diseño, desarrollo e implementación de la cultura organizacional en las entidades públicas, como desarrollo del Elemento de Control “Acuerdos, Compromisos y Protocolos Éticos - Modelo Estándar de Control Interno (Meci), adoptado por el Gobierno de Colombia mediante el Decreto n. ${ }^{0} 1599$ de 2005. 
actuación del servidor público contraria al interés público, bajo este código se atribuya a una conducta no propia y sea umbral que determine sanciones pecuniarias, jurídicas y demás. Vuelve y señala la USAID (2006, pp. 181-182):

Los Códigos de Ética son el documento de referencia para gestionar la ética en el día a día de la entidad. Está conformado por los Principios, Valores y Directrices que, en coherencia con el Código de Buen Gobierno, todo servidor público de la entidad debe observar en el ejercicio de su función administrativa. Características de los Códigos de Ética:

- Son marcos comunes de valores que orientan a la entidad hacia un horizonte ético compartido y que promueven el "vivir bien" y el "habitar bien" de los integrantes al interior de la organización y en la sociedad a la que pertenecen.

- Son documentos que establecen pautas de comportamiento de los servidores, y que señalan parámetros para la solución de los conflictos que puedan presentarse al interior de la entidad y con su entorno inmediato.

- Son textos que explicitan las respuestas que la entidad está dispuesta a dar a las obligaciones éticas con sus públicos internos y externos, dando cuenta de la calidad deseada de la acción social que la organización emprende.

Por cierto, los códigos de ética son un medio y no un fin en si mismos, son pautas orientadoras en la construcción de la confianza social frente al ejercicio de lo público, y no una probidad. Por otro lado, este código requiere de una estructura organizativa y, en especial, de un proceso de comunicación y pedagogía que fortalezca y codifique una cultura de la integridad, con beneficios como el servicio público, el uso de los bienes públicos, la responsabilidad y transparencia, la integridad de la administración y la humanización de la administración pública. Sin embargo, el código de ética simplemente como dispositivo de control no alcanza, en las organizaciones públicas pasar de ser simple requisito de la estructura administrativa-organizacional, para ser más que un código, un horizonte de sentido de reflexión que comprometa la libertad del servidor público hacia la pregunta por qué intereses e intencionalidades mueven su actuación pública y si está acorde con la finalidad y razón de ser de la institucionalidad a la que representa. Todo el modelo de gestión ética para las entidades del Estado colombiano a través del código de ética se enfoca, a buena hora, en la transparencia en el manejo de los recursos públicos.

Dicha transparencia compromete la generación de confianza por parte de los ciudadanos hacia la institucionalidad, que armonice conflictos y confronte intereses en un Estado democrático, pluralista y participativo. La generación de confianza sencillamente se diluye en la no transcendencia de la ética individualizada a esferas colectivas que comprometen modos de vida público. Para la USAID (2006, p. 37) “[...] la confianza es resultado de tres clases de juicios: de veracidad, de competencia y de inclusión”. El primero está en la congruencia entre el decir y el hacer; el segundo es el reconocimiento de capacidades propias y de otros para ejercer una labor; el último es la preocupación por el 
bienestar de otros, esto es, inclusión al colectivo en los beneficios de la acción que realiza el gobernante y el servidor público.

La esencia del modelo de gestión ética que fundamenta el código de ética está en el principio de transparencia, a su vez, tiene su condición de posibilidad en la nueva gestión pública que necesariamente problematiza la función pública desde criterios de desempeño y actuación que todo hombre público — servidor público - tiene y se le demanda. Igualmente, el manejo de los recursos públicos enfocados en el beneficio común está encaminado como código ético a partir del cumplimiento del artículo 209 de la Constitución Política de 1991, que expresa lo siguiente:

La función administrativa está al servicio de los intereses generales y se desarrolla con fundamento en los principios de igualdad, moralidad, eficacia, economía, celeridad, imparcialidad y publicidad, mediante la descentralización, la delegación y la desconcentración de funciones. Las autoridades administrativas deben coordinar sus actuaciones para el adecuado cumplimiento de los fines del Estado. La administración pública, en todos sus órdenes, tendrá un control interno que se ejercerá en los términos que señale la ley.

Precisamente la ética en las actuaciones del ejercicio público se enlaza en la función administrativa que necesariamente evoca principios morales en pro del cuidado de lo público, prevención y control. El código de ética está entre el deber ser como requisito administrativo y el poder ser como la siguiente pegunta: si se tiene un código de ética, ¿por qué no se denuncia las actuaciones fraudulentas que deslegitiman cada día la esencia del servidor e institucionalidad pública? En tanto, el poder ser se enfoca en "pensarnos y pensar a los otros" desde la voluntad, valores y principios del servidor público como sujeto ético, que reconoce y replantea modos de vida y actuar, en procura de ser congruente en la vida privada y la vida pública, como caras de una sola moneda. Asimismo, rechazar y sancionar lo contrario al bien común y la finalidad del Estado.

Por otro lado, la ética y transparencia en las actuaciones del ejercicio público es un trabajo formativo, esto surgiere el fortalecimiento de los postulados weberianos: responsabilidad y la convicción que orientan la decisión de actuar conforme a los principios públicos, que muchas veces se anteponen a las exigencias del contexto y del quehacer político viciado, ordenador de otras formas de obrar en lo público. Esto implica cambio en las percepciones y valoraciones internalizadas; también, constantemente cuestionamientos sobre la responsabilidad versus las acciones versus los intereses individuales y/o colectivos. Por tanto, a groso modo, los lineamientos del modelo de gestión ética para las entidades del Estado entregado por la USAID evidencian a través del código de ética como herramienta que no ha sido armonizada con los fines para los que fue concebida, como es la consolidación eficaz de una cultura de la integridad y trasparencia en la administración pública y no como una herramienta de codificación de lo que es propio a la construcción personal del hombre público, la conducta. 


\section{A modo de reflexión final}

La reflexión teórica del presente escrito en torno a la pregunta sobre la ética y lo público es reivindicar la acción pública y el bien común que recae sobre el hombre público — servidor público - y necesariamente no es una reflexión solo sobre la racionalidad de los valores - los medios y los fines que han de conducir la acción de este hombre- mediados por la responsabilidad y la convicción de este hombre público, sino, precisamente, reivindicar su humanidad ante un lugar público que lo enfrenta y lo pone en duda, puesto que el hombre público afronta su condición como sujeto histórico social. El hombre público es una construcción y producto histórico de una institucionalidad y finalidad pública y, desde luego, debe elaborar una tipología del ethos de lo político. Esto implica una postura crítica de sí mismo y de los otros en la manera como gobierna sus pasiones humanas — el amor, el odio, la pasión, el dolor, la compasión, la solidaridad, la ira, etc.para que sus percepciones y actuaciones sean cuestionadas por él mismo y por los otros, es decir, que sus pasiones sean gobernadas a partir de la razón, esto es, que toda acción pública se cuestione qué tanto conviene al bien común el actuar de determinada manera.

Si bien la ética es una cuestión ontológica, también es un argumento social, político y cultural posible. En esa medida, ¿cómo construir una ética de lo público? Para ello, necesariamente la revisión y establecimiento de acuerdos éticos que regulen la relación entre la ley, la moral y la cultura, y generen otros horizontes de sentido para afrontar las crisis de legitimidad en las instituciones públicas y sociales en las que se reproducen prácticas que socavan el bien común.

Para ello, según consideramos, el punto de partida de la revisión de la ética para el sector público y las acciones del hombre público es el cómo se reproducen las prácticas violentas e intimidación que instalan discursos y prácticas del miedo, que van desde la producción de sentimientos y emociones de odio y miedo, hasta la implementación de políticas en nombre de lo bueno y lo justo, que produce la eliminación simbólica y material del otro.

Cabe señalar que la relación entre la ética y lo público es la relación entre el dominio de las pasiones que caracterizan al político y al hombre público, mediante un profundo análisis de lo que hoy significa la responsabilidad y cuál es el sentido de su convicción, qué responsabilidad y convicción demanda el bien común y una sociedad política. De esta manera, todas las acciones públicas y el bien común que ejerce y al que está llamado el hombre público a cumplir, no solo como el conocimiento y la realización racional de acciones buenas, sino la formación de un hombre público que adquiere un sentido crítico de cómo se gobierna y cómo es gobernado por sus pasiones humanas, los códigos éticos, la institucionalidad y el mismo estado.

\section{Referencias}

Aristóteles. (1985). Ética A Nicómaco. Madrid: Gredos.

Arendt, H. (2005). La condición humana. Barcelona: Paidós Surcos.

Bautista, O. (2007). La ética en la gestión pública: fundamentos, estado de la cuestión y proceso para la implementación de un sistema ético integral en los gobiernos. Universidad 
Complutense de Madrid. Facultad de Ciencias Políticas y Sociología. Departamento de Ciencia Política y de la Administración. Disponible en: http://biblioteca.ucm.es/ tesis/cps/ucm-t29799.pdf

Constitución Política de Colombia de 1991. Temis,

Bautista, O. (2007). Ética y política: valores para un buen gobierno. Disponible en: http://eprints.ucm.es/6972/1/art-\%C3\%A9ticaypolitica-TI.pdf

Comisión Nacional del Servicio Civil (2015). Guia para establecer o modificar el Manual Especifico de Funciones y Competencias Laborales. Presentación EDL.

Constitución Política de Colombia de 1991. Temis. 2016

Congreso de la República. Ley 724 de 2002. Código Disciplinario Único.

Cortina, A. (1998). Hasta un pueblo de demonios. Ética pública y sociedad. Madrid.: Grupo Santillana de Ediciones.

Marco A. (2001). Meditaciones. Madrid: Cátedra.

North, D. (1993). Institución, cambio institucional y desempeño económico. México: Fondo de Cultura Económica.

Fernández, J. (2004). Apuntes para una teoría jurídica de las actividades del Estado. Revista Latinoamericana de derecho. Año I. n. ${ }^{\circ 2}$, pp. 35-70.

Fereira, E. (2005). Ética y valores en la nueva PDVsA, (presentación), Venezuela.

Gurza, A. (1998). Estado, Sociedad y Medios. Reivindicación de lo público. México: Plaza y Valdés Editores.

Gobernación de Antioquia. (2012). Código de Buen Gobierno. Disponible en: http:// antioquia.gov.co/PDF2/Codigo_de_BuenGobierno.pdf

Gunn, L. (1996). Perspectivas en gestión pública. Lecciones de Gestión Pública. Madrid: MAP, Madrid, pp. 41-45.

Procuraduría General de la Nación. (2015). Boletín 719 Corte Constitucional estudia demanda contra un aparte de la Ley 909 de 2004 que regula el empleo público, la carrera administrativa y la gerencia pública.

Procuraduría General de la Nación. (2006). Lecciones Derecho Disciplinario, volumen I. Bogotá: Instituto de Estudios del Ministerio Público.

Procuraduría General de la Nación. (2007). Lecciones Derecho Disciplinario, volumen II. Bogotá: Instituto de Estudios del Ministerio Público.

Rousseau, J. (1762). El contrato social. Disponible en: http://www.enxarxa.com/biblioteca/ROUSSEAU\%20El\%20Contrato\%20Social.pdf

Savater, F. (2003). El valor de elegir. Barcelona: Ariel.

Sánchez, A. (2007). Ética y política. México: Fondo de Cultura Económica.

Touraine, A. (1994/2000). ¿Quées la democracia? México: Fondo de Cultura Económica.

Urrego, G. (2015). Aproximación a los mecanismos de financiación de los gobiernos locales en Antioquia en el marco de la nueva gestión pública. Revista Entornos 28 (2), pp 60-77

USAID. (2006). Modelo de gestión ética para entidades del estado. Fundamentos conceptuales y manual metodológico. Disponible en: https://www.mineducacion.gov.co/ cvn/1665/articles-347277_archivo_pdf.pdf

Vanegas, J. (2010). Ética y derechos humanos en el marco de la constitución política de Colombia de 1991. Revista Jurid, pp. 74-92. Manizales: Universidad Autónoma de Manizales. Consultado en: http://juridicas.ucaldas.edu.co/downloads/ Juridicas7\%281\%29_5.pdf 
Valls, S. (2009). La noción del servicio público en el Estado Social de Derecho. Actualidad de los servicios públicos en México. México: Universidad Nacional Autónoma de México.

Weber, M. (1984). El politico y el cientifico. Madrid: Alianza. 